\title{
An Exploratory Study on Treatment Seeking Behavior and Pathways of Care Followed by Couples Attending Infertility Clinic
}

\author{
${ }^{1}$ Nitasha Sharma, ${ }^{2}$ Sunita Sharma, ${ }^{3}$ Sandhya Ghai, ${ }^{4}$ Inderjit Kaur, ${ }^{4}$ Jashanpreet Kaur, ${ }^{4}$ Harpreet Kaur
}

\begin{abstract}
Objective: The main aim of present study was to explore the treatment seeking behavior and pathways of care followed by couples attending infertility clinic at a tertiary care center.
\end{abstract}

Research design: The study adopted an exploratory research design. Using total enumeration technique a total of 40 infertile couples were interviewed using semistructured interview schedule.

Results: Out of total, $82 \%$ couples visited 1-4 healthcare agencies before coming to a tertiary care center. Among all treatment settings and options, majority $(62 \%)$ visited private health sector as first health agency. Based on first health agency visited a total of three care pathways were revealed with longest pathway comprised total of nine health agencies out of which four were private practitioners.

Conclusion: The infertile couples try varied forms of treatments before reaching a tertiary center shuttling from one agency to another. This drains them of all hope and energy for successful treatment.

Keywords: Infertile, Infertility, Pathways.

How to cite this article: Sharma N, Sharma S, Ghai S, Kaur I, Kaur J, Kaur H. An Exploratory Study on Treatment Seeking Behavior and Pathways of Care Followed by Couples Attending Infertility Clinic. Int J Infertil Fetal Med 2018;9(1\&2):1-5.

Source of support: Nil

Conflict of interest: None

\section{INTRODUCTION}

The prevalence of infertility around the world is approximately $5 \%{ }^{1}$ with at least 32 countries reporting more than $10 \%$ childlessness. ${ }^{2}$ The dimension of the problem can be judged from the fact that, one in every four couples

${ }^{1}$ Clinical Instructor, ${ }^{2}$ Lecturer, ${ }^{3}$ Principal, ${ }^{4}$ Nursing Intern

${ }^{1-4}$ National Institute of Nursing Education, Postgraduate Institute of Medical Education and Research, Chandigarh, India

Corresponding Author: Nitasha Sharma, Clinical Instructor, National Institute of Nursing Education, Postgraduate Institute of Medical Education and Research, Chandigarh, India, e-mail: nitasha470@yahoo.com suffer from infertility in developing nations. In India, the rough estimate suggests that nearly 30 million couples are suffering from infertility that makes the incidence rate of infertility about $10 \%{ }^{3}$ The psychological stress rooting from infertility is well recognized and studied among infertile couples. Infertile women report high levels of psychopathology in the form of tension, hostility, anxiety, depression, self-blame, suicidal ideation, anger, and frustration. ${ }^{4,5}$ There is a great deal of social stigma attached to infertility. ${ }^{6}$ Religious texts also single out infertile couples as the curse bearers. The society uses derogatory terms Bhanj or Waanj to refer to an infertile female. ${ }^{4}$ Thus, couples undergo feelings of sadness, pain and emptiness. Others report feeling down, left out, heartbroken, a deep longing inside and inadequacy. At times their issue of infertility becomes the talking point of the town. The infertile couples have to answer the awkward queries thrown at them by the community, and they often become part of their jokes. In the case of male infertility, men feel that their social status is affected, not respected, not considered adults and are not treated as a man. Men usually tend to hide their problem. They vent out their feelings of anger, frustration, and helplessness on their better half. Some men also report feeling ashamed and embarrassed. ${ }^{6}$

In a country like India, childbearing seems like an innate desire of every couple. The various reasons cited by them for childbearing are broadly based upon the family perspective, social perspective, and religious perspective. Here, people seek alternative forms of treatment to avoid the consequences of childlessness rather than adopting assistive reproductive technologies. Besides this, they often use various religious practices and traditional methods to meet the ends. They may visit astrologers, participate in rituals, observe fasts or tantric rites, wear charms or amulets and visit temples. Very few of them visit assisted reproductive technology centers as the first treatment option, others try their luck with Ayurveda, homeopathy and Unani systems of medicine. Some also follow treatment combinations. But in most cases, the advice of quacks, religious leaders and spiritual healers have sought after. This whole process undertaken to bear a child becomes laborious as well as emotionally, 
physically and financially exhaustive for the couple. So finally, when the couple manages to reach the infertility clinic, he/she is fully drained of energy and hopes. By that time, the ages of eligible females have advanced, and others have developed other physical and mental comorbidities. These have a direct and indirect impact on the outcome of assistive reproductive treatments. So far, no such investigation has been carried out in current geographic setting to assess the treatment-seeking behavior and identify care pathways followed by infertile couples before landing in an infertility clinic. The purpose of the present study is to assess the care pathways followed by the infertile couples before reaching the infertility clinic.

\section{METHODOLOGY}

The main aim of the present study was to explore the treatment-seeking behavior and pathways of care followed by infertile couples attending the infertility clinic at a tertiary care center. An exploratory research design was adopted for the study. The study was conducted at the infertility clinic of a 2000 bedded tertiary care hospital in North India. On an average 20 intrauterine inseminations (IUIs) are performed daily and the average success rate of IVIs performed here is around 25\%. Using total enumeration technique a total of 40 infertile couples attending infertility clinic in the month of data collection were enrolled in the study. The researcher developed an interview schedule to fulfill the study objectives. The interview schedule comprised of three sections. The first section was the sociodemographic profile sheet for couple, the second section included the clinical profile sheet, and the third section was a semistructured interview schedule for assessing treatment-seeking behavior of infertile couples: The questionnaire included information such as source of referral, all forms of treatment opted by couple, type of health sectors approached and the number of visits made and outcomes of the various treatments. The face and content validity of tool was done by various experts from the field of gynecology, obstetrical nursing and social work. The Ethical clearance was taken from the Institute's Ethics Committee. Each participant was explained about the purpose of the study and written informed consent was obtained. The data were collected in a special interview room near the infertility clinic. The room was conducive to ensure privacy and confidentiality. The couples were given due time and support to express themselves through empathic listening.

The semistructured interviews were conducted and audiotaped by the researcher. It took around 45 minutes to complete the interview in each couple. The important, relevant information was then extracted from the verbatim.
The quantitative data were analyzed using Microsoft Excel, SPSS 19 version and using relevant descriptive statistics. The findings were presented in the form of tables and figures whereas the pathways of care were developed from interview narratives and presented in the form of flowcharts.

\section{RESULTS}

Table 1 depicts the socio-demographic profile of study participants. Majority of females attending infertility clinic were in the age range of 21-29 years, with education up to secondary level and were homemakers. Majority of males were in the age group above 30 years with education up to secondary and were engaged in a private job. Majority of couples belonged to Hindu joint family of urban background with per capita income between 5000 and 15000.

Table 2 depicts the clinical profile of infertile female participants. Majority of them had primary infertility. The mean duration of infertility was $<5$ years in the majority of females. Majority of them did not have menstrual irregularities' nor had a family history of infertility. Total $45 \%$ of them reported the use of psychoactive substance including tobacco in their partners. It was found that $22 \%$ of them had tubal blockade while $15 \%$ had ovarian cysts.

Table 1: Sociodemographic profile of study samples $(n=40)$

\begin{tabular}{|c|c|c|}
\hline Sociodemographic variables & $\begin{array}{l}\text { Wife } \\
f(\%)\end{array}$ & $\begin{array}{l}\text { Husband } \\
f(\%)\end{array}$ \\
\hline \multicolumn{3}{|l|}{ Age } \\
\hline - 21-29 & $23(58)$ & $14(35)$ \\
\hline - 30 and above & $17(42)$ & $26(65)$ \\
\hline \multicolumn{3}{|l|}{ Education } \\
\hline - Illiterate & $3(8)$ & - \\
\hline - Primary & $1(2)$ & - \\
\hline - Secondary & $20(50)$ & $22(55)$ \\
\hline - Graduate & $8(20)$ & $15(38)$ \\
\hline - Postgraduate & $8(20)$ & $3(7)$ \\
\hline \multicolumn{3}{|l|}{ Occupation } \\
\hline - Unemployed/housewife & $30(75)$ & $2(5)$ \\
\hline - Agriculture & - & - \\
\hline - Business & - & $6(15)$ \\
\hline - Private job & $8(20)$ & $24(60)$ \\
\hline - Government job & $2(5)$ & $8(20)$ \\
\hline \multicolumn{3}{|l|}{ Family type } \\
\hline - Nuclear & $11(28.0)$ & \\
\hline - Joint & $29(72)$ & \\
\hline \multicolumn{3}{|l|}{ Locality } \\
\hline - Urban & $19(48)$ & \\
\hline - Rural & $21(52)$ & \\
\hline \multicolumn{3}{|l|}{ Per-capita income } \\
\hline - $<5000$ & $2(5.0)$ & \\
\hline - 500-15000 & $36(90.0)$ & \\
\hline - 15001-25000 & $2(5.0)$ & \\
\hline \multicolumn{3}{|l|}{ Religion } \\
\hline - Hindu & $24(60.0)$ & \\
\hline - Muslim & $5(13)$ & \\
\hline - Sikh & $10(25)$ & \\
\hline - Christian & $1(2.0)$ & \\
\hline
\end{tabular}


An Exploratory Study on Treatment Seeking Behavior and Pathways of Care Followed by Couples Attending Infertility Clinic

\begin{tabular}{|c|c|}
\hline Clinical profile characteristics & $\begin{array}{l}\text { Wife } \\
f(\%)\end{array}$ \\
\hline \multicolumn{2}{|l|}{ Infertility type } \\
\hline - Primary & $29(72.0)$ \\
\hline - Secondary & $11(28.0)$ \\
\hline - Had atleast one pregnancy $>28$ weeks & $2(5.0)$ \\
\hline - Never had a pregnancy $>28$ weeks & $9(22.5)$ \\
\hline \multicolumn{2}{|l|}{ No. of live children } \\
\hline - Atleast one & $2(5.0)$ \\
\hline - None & $38(95.0)$ \\
\hline \multicolumn{2}{|l|}{ Duration of infertility } \\
\hline - $<5$ years & $30(75.0)$ \\
\hline - $>5$ years & $10(25.0)$ \\
\hline \multicolumn{2}{|l|}{ Menstrual irregularities } \\
\hline - Yes & $12(30.0)$ \\
\hline - No & $28(70.0)$ \\
\hline \multicolumn{2}{|l|}{ Family history of infertility } \\
\hline - Yes & $10(25.0)$ \\
\hline - No & $30(75.0)$ \\
\hline \multicolumn{2}{|l|}{ Psychoactive substance use in partner } \\
\hline - Yes & $18(45.0)$ \\
\hline - No & $22(55.0)$ \\
\hline
\end{tabular}

Table 3 depicts the treatment-seeking behavior of infertile couples. It was seen that almost $82 \%$ of couples had visited 1-4 helping agencies before coming to the tertiary care center. For the majority of couples the private sector was the first health agency visited. In the majority of cases, the initiative for treatment was taken by females.

Based upon the verbatim of interviews conducted to understand pathways of care, the researcher could develop a total of three pathways based upon the first agency visited as an initial point of reference.

Flow chart 1 depicts that a total of 25 couples started the care pathway by visiting a private practitioner. These 25 couples further opted for subsequent agencies of help. Only 4 of them visited tertiary care center as second agency thus generated the shortest pathway. The longest

Table 3: Treatment seeking behavior of infertile couples

$f(\%)$

No. of health sectors visited before coming to tertiary center

$1-4$

58

First helping agency visited

Traditional healer

Private health sector

$25(62.5)$

Public health sector

$10(25)$

AYUSH

Initiative taken by

Self (wife)

$23(58.0)$

Couple

$10(25.0)$

Family/relatives

$7(17.0)$

Source of referral to tertiary centre

Self

$20(50.0)$

Relatives/colleagues

$10(25.0)$

Doctor

$10(25.0)$

pathway comprised of a total of nine health agencies out of which four were private practitioners.

Flow chart 2 depicts the care pathway for four couples who initiated treatment from a traditional system and further opted for other agencies. In this case, also the most extended trail involved six agencies out of which three were private practitioners.

Figure 3 depicts the pathway of care for the couples who initiated with a public sector health agency followed by a combination of other such agencies. The shortest pathway here comprised only two stations while the longest involved five health agencies out of which three were private.

\section{DISCUSSION}

Being infertile means carrying baggage along with oneself. This sociomedical problem poses a significant threat to all the aspects of wellbeing like physical,

Flow chart 1: Care pathways of those who first visited the private sector $(n=40)$

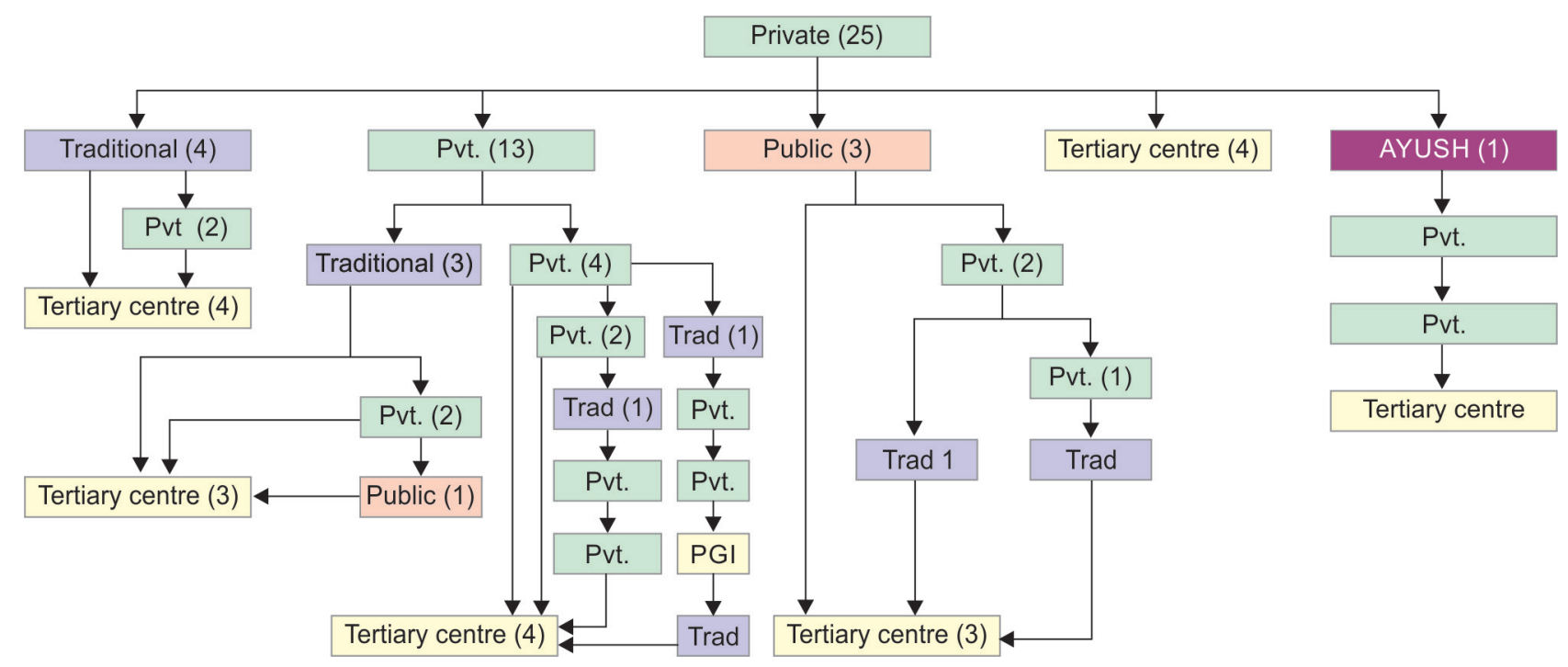


Flow chart 2: Pathways of couples who first visited traditional sector $(n=40)$

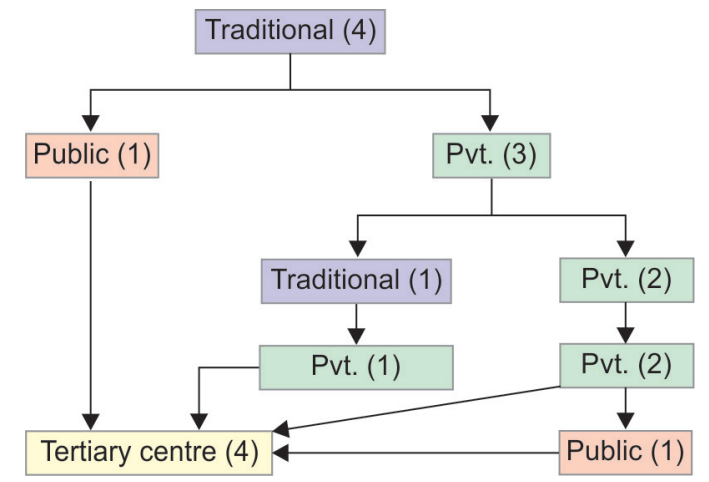

emotional, psychological and social. Such factors make treatment seeking high in infertile couples. In the present study, the treatment-seeking behavior of infertile couples was assessed to generate the care pathway followed by them while starting from first health agency to a tertiary care center. It was seen that as expected almost $82 \%$ of couples had visited 1-4 agencies before visiting the tertiary care center while remaining had visited 5-8 such agencies. These estimates are very close to the results of one the largest cross-sectional survey covering 6,43,944 infertile women in India who reported the percentage of women seeking treatment for lifetime primary and current primary infertility are around $83 \%{ }^{7}$ The assessment on health agency first visited for treatment of infertility revealed that a major section of affected couples initiated the treatment from allopathic practitioners. Such a pattern of treatment seeking was also reported from a similar survey by Sarkar where it was only 33\% of affected couples who opted for traditional and nonallopathic treatment for infertility. ${ }^{8}$

The detailed observation of the care pathways reveals that the longest pathway included a total of nine health agencies percouple.Similar findingswere reported inastudy where most patients had seen between 1 and 3 specialists, $20 \%$ had seen between 4 and 6, while the highest number of specialists visited by a respondent was $12 .{ }^{7}$ The authors also reported that $87 \%$ of the couples reported switching between providers. In the current study, switching was indeed very common in more than $90 \%$ couples.

India, being a land of many religions and cultures, people have immense faith in traditions and beliefs. As observed almost all couples had one or the other point of time had approached a traditional healer during treatment. The treatment offered by the traditional healer was in the form of tablets, powder, and syrup. The couples reported taking tablets with cow's milk. Religion being part and parcel of life in India, couples observed fasts, havans and chanted prayers too. The care pathways revealed that treatment for infertility though is initiated by couples at an appropriate time, however, the switch
Flow chart 3: Care pathways of couples who first visited the public $(n=40)$

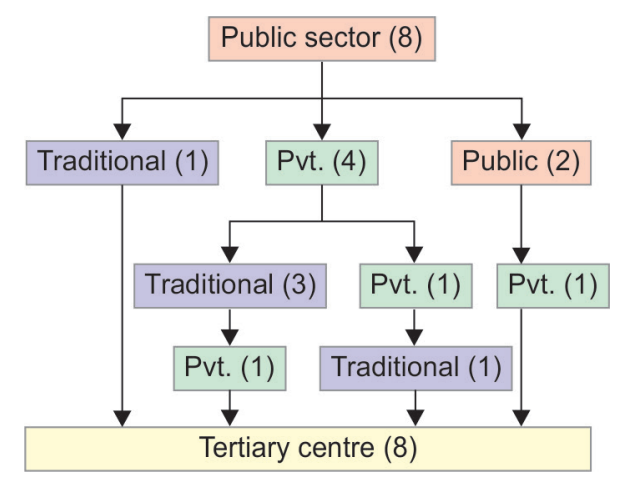

from one agency to other causes unnecessary delays in the successful treatment. The most observable phenomenon was that the longest pathways had a number of private practitioners. This poses the question on the quality of services rendered by such private practitioners as the switch is very high. Moreover, repeated failures or switch without successful outcomes often drain the couples of all hope and optimism which affects the outcome of treatment.

The present study provided the apparent snapshot on care pathways of infertility. The study provides a distinct view on help-seeking agencies most often utilized by infertile couples. The study did not explore the out of pocket expenditure in each agency. Further, the specific reasons for the switch were not studied. Some of the pathways might have been associated with a great deal of frustration and depression which was however not reported in the results. It is further recommended to understand treatment seeking in greater depths knowing the exact causes of the switch. It is also recommended to study the correlates and predictors of longer pathways.

\section{CONCLUSION}

Infertile couple visit various healthcare agencies before reaching a tertiary care centre for assisted reproductive technologies resulting in long pathways of care. Eighty two percent of them have visited 1-4 agencies before coming to a tertiary care centre. The longest pathway has nine healthcare agencies with majority visiting private practitioner as first agency.

\section{REFERENCES}

1. Global prevalence of infertility, infecundity and childlessness-sexual and reproductive health.Human Reproduction Programme, WHO. Available at http:/ / www.who.int/reproductivehealth/topics/infertility/burden/en/. Accessed on 3 June 2016

2. Ram U. Childlessness in time, space and social groups and its linkages with fertility in India. Available at http:// www.infostat.sk/vdc/epc2006/papers/epc2006s60100. pdf. Acessed on 2016, 8 Aug. 
3. Express News Service. 30 million couples in India suffer from Infertility. The Indian Express. Accessed on 10 March 2010.

4. Ramezanzadeh F, Aghssa MM, Abedinia N, Zayeri F, Khanafshar N, Shariat M, Jafarbadi M. A survey of relationships between anxiety, depression and duration of infertility. BMC Women's Health. 2004;4(9).

5. Lok IH, Lee DT, Cheung LP, Chung WS, Lo WK, Haines CJ. Psychiatric morbidity amongst infertile Chinese women undergoing treatment with assisted reproductive technology and the impact of treatment failure. Gynecologic and obstetric investigation. 2002;53(4):195-199.

6. Lok IH, Lee DT, Cheung LP, Chung WS, Lo WK, Haines CJ. Psychiatric morbidity amongst infertile Chinese women undergoing treatment with assisted reproductive technology and the impact of treatment failure. Gynecologic and obstetric investigation. 2002;53(4):195-199.

7. Infertility and Treatment Seeking in India: Findings from District Level Household Survey.Unisa S . Facts, Views \& Visions. Issues in Obstertrics, gynaecology \& Reproductive Health. Available at http://www.fvvo.be/monographs/ social-aspects-of-accessible-infertility-care-in-developingcountries/infertility-and-treatment-seeking-in-india-findings-from-district-level-household-survey/. Accessed on 22 Sept 2016.

8. Sarkar S, Gupta P. Socio-Demographic Correlates of Women's Infertility and Treatment Seeking Behavior in India. J Reprod Infertil. 2016;17(2):123-132. 